\title{
Consistency of Nursing Directors, Nursing Supervisors, and Nursing Quality Specialists' Perception about Nursing-Sensitive Indicators in Acute Care Settings
}

\author{
Tareq Afaneh $^{*}{ }^{(\mathbb{C}}$, Fathieh Abdullah Abu-Moghli² ${ }^{2}$ \\ ${ }^{1}$ King Hamad University Hospital, Muharraq, Bahrain \\ ${ }^{2}$ Community Health Nursing Department, School of Nursing, The University of Jordan, Amman, Jordan \\ Email: *tariqa_1917@yahoo.com, fathieh@ju.edu.jo
}

How to cite this paper: Afaneh, T. and AbuMoghli, F.A. (2020) Consistency of Nursing Directors, Nursing Supervisors, and Nursing Quality Specialists' Perception about Nursing-Sensitive Indicators in Acute Care Settings. Open Journal of Nursing, 10, 705715.

https://doi.org/10.4236/ojn.2020.107050

Received: June 16, 2020

Accepted: July 17, 2020

Published: July 20, 2020

Copyright $\odot 2020$ by author(s) and Scientific Research Publishing Inc. This work is licensed under the Creative Commons Attribution International License (CC BY 4.0).

http://creativecommons.org/licenses/by/4.0/

\begin{abstract}
Introduction: Nursing-Sensitive Indicators (NSIs) is a critical concept for the advancement of the nursing profession. However, different managerial positions may have a different perspective on the appropriate NSIs that should be used in hospitals for the monitoring of nursing care quality. This study aims to find if there is a difference between three groups of nursing managerial positions on the appropriateness of NSIs for the monitoring of nursing care quality. Methods: Descriptive cross-sectional approach was employed to evaluate if there is a difference among the three managerial groups in their evaluation for the appropriateness of using a cluster of NSIs in acute care settings. The study was conducted in Jordan between February and March 2020. Result: The study participants were 60 nurses from different managerial positions. The mean scores of the participants were: directors of nursing (200.6), nursing supervisors (199.1), and nursing quality specialists (198.62). The findings revealed no statistical difference between the three groups of their evaluation of the appropriateness of the NSIs. Conclusion: Standardizing the nursing mangers perspectives of NSIs may advance utilization of the NSIs for the monitoring and reporting of nursing care quality. Implications for Nursing Management: Consistent understanding of the measures that can be used to monitor quality of nursing care can establish the foundation for quality measurement and quality improvement in acute care settings.
\end{abstract}

\section{Keywords}

Nursing-Sensitive Indicators, Quality of Nursing, Acute Care Settings, Nursing Managers 


\section{Introduction}

During the Crimean ware, the British government sent Florence Nightingale and a group of nurses to Turkey to care for the soldiers. Cholera and diarrhea were responsible for mortality of many soldiers. Within six months from their arrival, mortality rate dropped from $42.7 \%$ to $2.2 \%$ [1]. Nightingale accomplishments included improving of ventilation, preventing patients crowding by separating their beds, removing of Calvary horses that were being stabled in the hospital provision, and guaranteeing the hospital drains were flushed several times a day and disinfecting them [2]. She was the first to publish suggestions on improving the outcomes of care based on a statistical measurement approach [3].

In 1995, the American Nursing Association launched the Nursing's Safety and Quality Initiative. This effort proposed and implemented nursing quality indicators (Thomas-Hawkins, 2017). The concept "nursing-sensitive outcome indicator" was first prescribed in 1996 by Mas et al., not as a quantitative system indicator, but to describe patient states that are sensitive to nursing interventions (Maas, Johnson, \& Moorhead, 1996). Dubois and D'Amour [4] advocate that conceptualization of nursing performance can create an advantage of combining more than one model guided by theoretical foundation that can provide "accurate picture of nursing system performance.

Despite its importance, the fuzzy use of NSIs concept hinders comprehensive organized efforts for improving quality of nursing performance [5]. Burston and Chaboyer [6] conducted a literature review of NSIs and found that despite the regular use of Donabedian's [7] framework of quality assessment, there is inconsistency between the concept and the use of commonly identified indicators. This inconsistency is related to variation in conceptual definition of NSIs and methodological approach for developing sets of NSIs. Agencies like the National Quality Forum, the American Nurses Association and the Agency for Healthcare Research and Quality attempted to standardize the development and measurement of NSIs, but there is no agreement on what constitute NSIs [6].

In practice, healthcare organizations still select potentially nursing-sensitive indicators among enormous list of indicators which deprive policy makers and nursing leaders from viewing the full and accurate picture of nursing contribution to quality of healthcare [8]. Therefore, nurses in the managerial positions need to have a standardized approach for measuring quality of nursing performance based on a carefully selected set of NSIs.

Failure to provide nursing leaders with an approach for quantifying quality of nursing performance deprives them from the opportunity of owning measurable evidence on the impact of nursing system characteristics on patient outcomes [6]. This study aims to explore if there is a difference between three groups of managers on the appropriateness of NSIs for the monitoring of nursing care quality in acute care setting.

\section{Methods}

A systematic literature review was conducted to identify potential NSIs. The search 
was performed using PubMed search engine. The subject heading "nurs* sensitive indicators" was entered. In addition, MEDLINE and CINAHL full text in EBSCOhost databases were searched. The search included full text articles published in English from 2010 to 2020. The review process resulted in identifying 52 NSIs which have the potential to be used for monitoring quality of patient care in acute care settings (Appendix A).

The study instrument was developed by the researchers based on the review of the literature. The instrument involves two sections. First section includes the demographic and professional characteristics, while the second includes a list of 52 indicators NSIs that were grouped into structure, process, and outcome indicators [7].

A 5-points scale; strongly disagree, disagree, don't know, agree, and strongly agree was used to evaluate level of agreement of the participants for the appropriateness of NSIs in monitoring nursing care quality. The 5-point scale is most common scale when the level of agreement is investigated [9].

Psychometric properties of the developed tool were observed using a group of procedures. Cohen's kappa coefficient $(\mathrm{K})$ is used to measure inter-rater for categorical items. [10]. Cohen's kappa $(\mathrm{K})$ was used to assess Inter-rater reliability. The $\mathrm{K}$ value is 0.47 which indicates moderate agreement [11]. Internal consistency reliability was evaluated using Cronbach's Alpha. The structure indicators subscale Cronbach's Alpha values is 0.90 , the process indicators subscale Cronbach's Alpha values is 0.91 , while the outcomes indicators subscale Cronbach's Alpha values is 0.89 . The total scale Cronbach's Alpha value is 0.94 indicating excellent Internal Consistency Reliability. The Content Validity Index (CVI) of the instrument was 0.83 .

The sample of the present study includes 65 nurses in managerial positions (Directors of nursing, nursing supervisors, and nursing quality specialist). The study used proportionate purposive sampling to determine the sample size. Hospitals with highest $15 \%$ - 20\% of nursing workforce among different healthcare sectors are identified. Directors of nursing, nursing supervisors, and nursing quality specialist of those hospitals were invited to participate in the study. Based on this sampling strategy, the expected number of the participants was $57-72$.

The selection criteria were developed based on a group of expert attributes. The criteria included nursing academic background with a minimum of bachelor degree qualification, being a registered nurse, current position as director of nursing, nursing supervisor, or nursing quality officers, English language proficiency, and willingness to participate in the study.

The participants were invited to participate in the study through using Internet Data Collection (IDC). IDC provides an access to unique and diverse respondents in cost effective manner while providing instant data capturing in an electronic formats [10].

Participants' responses were transferred to SPSS Statistics 22.0 for Windows [12]. One-Way Analysis of Variance (ANOVA) was utilized to examine if there is a significant statistical difference between mean scores on rating NSIs among 
three groups. The dependent variable "total score" was calculated by addition of the participants' responses for the 5 points Likert scale made from 52 items, the scale measured patient this addition yielded a possible scores ranging from 52 to 260.

Data collection process took place on February and March 2020. The study took place in 27 hospitals from both public and private sectors hospitals in Jordan. IRB Approvals of the participating hospitals where obtained. Informed consents were secured from all participants prior to sending the study questionnaire.

\section{Results}

Of the 65 participants of the workshop, 60 completed the study equivalent to a response rate of $92.3 \%$. The demographic characteristics are presented in Table 1. The findings indicate that the participants represent various nursing administrative levels including directors of nursing, nursing supervisors, and nursing quality officers. Participants' age ranged from 25 to 62 years $\mathrm{M}=40.63, \mathrm{SD}=7.5$. Almost all the participants held a bachelor or master degree qualification 37 (61.7), 20 (33.3) respectively.

To run an ANOVA test, three assumptions were tested, these assumptions are: The dependent variable is continuous and approximately normally distributed, this assumption was tested using skewness test which revealed a skewness value of (0.54) which indicates moderate skewness, mean (199.32), median, (198.00), and standard deviation (7.62) (Wegner, 2016). The independent variable "participant position" has independent observation "mutually exclusive observations" this assumption was met for the independent variable as each participant was assigned to one group only. Homogeneity of variance, the Levene test for homogeneity of variance was used to examine whether there were serious violations of the assumption of homogeneity of variance across groups, no significant violation was found: $\mathrm{F}(2,52)=2.80, \mathrm{P}=0.07$. The findings presented in Table 2

Table 1. The demographic characteristics.

\begin{tabular}{cccccc}
\hline Demographic d & N (\%) & Min & Max & Mean (SD) & Median \\
\hline Age & & 25 & 62 & $40.63(7.50)$ & 40.50 \\
Current Position & & & & & \\
Director of Nursing & $15(25)$ & & & & \\
Nursing Supervisor & $21(35)$ & & & & 5 \\
Quality Officer & $24(40)$ & & & & 18.5 \\
Experience in Current Position (years) & & 1 & 25 & $6.20(5.30)$ & \\
Total Experience (years) & & 6 & 36 & $18.47(7.10)$ & \\
Academic Qualification & & & & & \\
Doctorate & $3(5.0)$ & & & & \\
Master & $20(33.3)$ & & & & \\
Bachelor & $37(61.7)$ & & & & \\
Hospital Bed Capacity & & 42 & 678 & $266.27(157.84)$ & 200 \\
\hline
\end{tabular}


Table 2. Total score of NSIs per nursing group.

\begin{tabular}{cccc}
\hline Group & Mean (SD) & F & Significance \\
\hline Directors of nursing & $200.60(8.21)$ & & \\
Nursing supervisor & $199.10(5.10)$ & 0.30 & 0.07 \\
Nursing quality officers & $198.62(9.19)$ & & \\
Total & $199.32(7.62)$ & & \\
\hline
\end{tabular}

show that there is no statistical among three groups in their rating of NIS, F = $0.3, P=0.07$. This finding indicates that there is no statistically significant difference among directors of nursing, nursing supervisors, and nursing quality specialist perception about the appropriateness of NSIs to monitor nursing care quality.

\section{Discussion}

\subsection{NSIs}

NSIs provide nursing leaders with an approach to quantify and monitor quality of nursing care and the quality of nursing system as a whole to enhance decision-making [5]. Furthermore, NSIs play an important role in identifying priority areas for improving nursing care and to direct improvement efforts towards these priority areas [13]. Measuring and monitoring the quality of nursing care in hospitals is viewed as a prerequisite for improving the quality of care provided to patients. NSIs form the basis for monitoring the quality of nursing performance. They provide nursing mangers with a tool to guide organizational improvement and with a common ground for national benchmarking of nursing performance between healthcare organizations [8]. Additionally, as nursing is a profession that has its unique scope of practice, nurses must have their unique system for monitoring the quality of care provided to patients.

Discrepancy across different nursing staff roles in the perception about meaning of NSI may lead to problems with implementation of quality improvement efforts. Establishing structures, process, and outcome NSIs could facilitate cross understanding of measuring quality of nursing within nursing workforce to convey explicit interpretations for quality of nursing care. Eventually, achieving an understanding of NSIs requires a holistic approach to training that enables individuals to learn not only the concept of quality measurement but also how to operationalize the concept. Previous Studies found perspectives on quality vary between nursing managers from one side and practicing nurses on the other side. [14]. In addition, frontline staff use of data for quality improvement on a department level was found to be different from the use of nursing managers [15].

Findings of the present study shows that there is no statistical difference between the three group of participants; directors of nursing, nursing supervisor, nursing quality officers in their evaluation of the appropriateness of the NSIs for 
use in acute care settings. Nursing managers understanding of the NSIs and their appropriateness can be beneficial to nursing practice as nursing care quality can be quantified and measured. Measuring and monitoring the quality of nursing care in hospitals is viewed as prerequisite for improving the quality of care provided to patients. NSIs form the basis for monitoring quality of nursing performance. They provide nursing managers with a tool to guide improvement of quality of nursing care and with a common ground for inter-departmental as well as inter-organizational benchmarking of nursing performance between healthcare organizations [8].

\subsection{Implications}

Consistency by the nursing managers on the appropriateness of NSIs is an important requirement for the advancement of the nursing profession. It supports the advancement of nursing research attempts to provide scientific evidence on the impact of nurses and nursing profession on health outcomes and o healthcare system. This can be advanced through standardizing the utilization and reporting of the NSI in acute care settings. The study contributes to standardize adopting a set of indicators for monitoring and reporting quality of nursing performance.

Nursing directors, nursing supervisors, and nursing quality specialist share a common ground of monitoring and improving nursing care quality. Therefore, Nursing research that aims to strengthen the understanding and use of NSIs and for developing NSIs for clinical practice must continue because nursing managers need a standardized approach for measuring the quality of nursing performance.

\subsection{Limitations}

The present study has some limitations. First, the survey was conducted in hospitals in Jordan, restricting generalization of the study findings to other countries. Second, the sample size of the study was minimal as it was limited to a unique population. Third, psychometric evaluation of the tool was conducted using inter-rater reliability, internal consistency reliability, content validity. Further validation using other methods, such as construct validity assessment confirmatory factor analysis or known-groups method, is needed to strengthen the validity of NSIs tool. In addition, only internal consistency reliability of NSIs was assessed using Cronbach's alpha coefficient.

\section{Conclusion}

In order to provide solid evidence on the impact of the quality of nursing performance on health and healthcare systems, nurses from different managerial positions need to speak the same language. Maturation of NSIs concept, agreement on the appropriate NSIs, and adopting NSIs to monitor quality of nursing care can advance a shared vision towards the impact of nursing profession on 
healthcare quality. The findings of present study support evidence on the similar understanding of nurses in managerial positions regarding NSIs. Nursing managers shared understanding of the NSIs and their appropriateness can be beneficial to nursing practice as nursing care quality can be measured and improved.

\section{Author's Contributions}

\section{Tareq Afaneh}

Conceived and conducted the study.

\section{Fathieh Abu-Moghli}

Provided overall supervision of the work and critical revision of the paper, and contributed to the conception and conduction of the study.

\section{Funding}

This research received no grant from any funding agency in the public, commercial, or not-for-profit sectors.

\section{Conflicts of Interest}

The authors certify that they have NO conflict of interest with respect to the research, authorship, and/or publication of this article.

\section{References}

[1] Sheingold, B.H. and Hahn, J.A. (2014) The History of Healthcare Quality: The First 100 Years 1860-1960. International Journal of Africa Nursing Sciences, 1, 18-22. https://doi.org/10.1016/j.ijans.2014.05.002

[2] Nightingale, F. (1863) Notes on Hospitals. Longman, Green, Longman, Roberts, and Green, London.

[3] Brown, J.A. (2017) The Healthcare Quality Handbook: A Professional Resource and Study Guide. 29th Edition, JB Quality Solutions, Inc., Pasadena.

[4] Dubois, C.A., et al. (2013.) Conceptualizing Performance of Nursing Care as a Prerequisite for Better Measurement: A Systematic and Interpretive Review. BMC Nursing, 12, Article No. 7. https://doi.org/10.1186/1472-6955-12-7

[5] Kieft, R.A.M.M., Stalpersb, D., Jansena, A.P.M., Franckecd, A.L. and Delnoijef, D.M.J. (2018) The Methodological Quality of Nurse-Sensitive Indicators in Dutch Hospitals: A Descriptive Exploratory Research Study. Health Policy, 122, 755-764. https://doi.org/10.1016/j.healthpol.2018.05.015

[6] Burston, S., Chaboyer, W. and Gillespie, B. (2014) Nurse-Sensitive Indicators Suitable to Reflect Nursing Care Quality: A Review and Discussion of Issues. Journal of Clinical Nursing, 23, 1785-1795. https://doi.org/10.1111/jocn.12337

[7] Donabedian, A. (1988) The Quality of Care: How Can It Be Assessed? Journal of the American Medical Association, 260, 1743-1748.

[8] Dubois, C.A., et al. (2017) Which Priority Indicators to Use to Evaluate Nursing Care Performance? A Discussion Paper. Journal of Advanced Nursing, 73, 3154-3167. https://doi.org/10.1111/jan.13373

[9] Giannarou, L. and Zervas, E. (2014) Using Delphi Technique to Build Consensus in Practice. International Journal of Business Science \& Applied Management (IJBSAM), 
9, 65-82.

[10] Waltz, C.F., Strickland, O. and Lenz, E.R. (2017) Measurement in Nursing and Health Research. https://doi.org/10.1891/9780826170620

[11] Landis, J.R. and Koch, G.G. (1977) The Measurement of Observer Agreement for Categorical Data. Biometrics, 33, 159-174. https://doi.org/10.2307/2529310

[12] IBM Corp (2013) IBM SPSS Statistics for Windows, Version 22.0. IBM Corp, Armonk, NY.

[13] Sim, J., et al. (2019) Development of a Data Registry to Evaluate the Quality and Safety of Nursing Practice. Journal of Advanced Nursing, 75, 1877-1888. https://doi.org/10.1111/jan.13967

[14] Price, M., Fitzgerald, L. and Kinsman, L. (2007) Quality Improvement: The Divergent Views of Managers and Clinicians. Journal of Nursing Management, 15, 43-50. https://doi.org/10.1111/j.1365-2934.2006.00664.x

[15] Egholm, C.L., et al. (2019) Facilitators for Using Data from a Quality Registry in Local Quality Improvement Work: A Cross-Sectional Survey of the Danish Cardiac Rehabilitation Database. BMJ Open, 9, 1-10. https://doi.org/10.1136/bmjopen-2018-028291

[16] Whitman, G.R., et al. (2002) The Impact of Staffing on Patient Outcomes across Specialty Units. The Journal of Nursing Administration, 32, 633-639. https://doi.org/10.1097/00005110-200212000-00008

[17] NDNQI (2010) National Database of Nursing Quality Indicators (NDNQI).

[18] Jordanian Nursing Council (2016) National Strategy for Nursing and Midwifery: A Road Map to 2025 for Jordan. JNC. http://www.jnc.gov.jo/

[19] Ministry of Health (2018) Ministry of Health Strategic Plan 2018-2022. http://www.moh.gov.jo/

[20] Stalpers, D., et al. (2016) Using Publicly Reported Nursing-Sensitive Screening Indicators to Measure Hospital Performance: The Netherlands Experience in 2011. Nursing Research, 65, 362-370. https://doi.org/10.1097/NNR.0000000000000170

[21] Stalpers, D., et al. (2016) Concordance between Nurse-Reported Quality of Care and Quality of Care as Publicly Reported by Nurse-Sensitive Indicators. BMC Health Services Research, 16, 120-120. https://doi.org/10.1186/s12913-016-1372-Z

[22] Sovie, M.D. and Jawad, A.F. (2001) Hospital Restructuring and Its Impact on Outcomes: Nursing Staff Regulations Are Premature. The Journal of Nursing Administration, 31, 588-600. https://doi.org/10.1097/00005110-200112000-00010

[23] Aiken, L.H., et al. (2002) Hospital Nurse Staffing and Patient Mortality, Nurse Burnout, and Job Dissatisfaction. Jama, 288, 1987-1993.

https://doi.org/10.1001/jama.288.16.1987

[24] Yang, K.-P. (2003) Relationships between Nurse Staffing and Patient Outcomes. The Journal of Nursing Research: JNR, 11, 149-158. https://doi.org/10.1097/01.JNR.0000347631.87723.de

[25] Shuldham, C., Parkin, C., Firouzi, A., Roughton, M. and Lau-Walkerb, M. (2009) The Relationship between Nurse Staffing and Patient Outcomes: A Case Study. International Journal of Nursing Studies, 46, 986-992. https://doi.org/10.1016/j.ijnurstu.2008.06.004

[26] Twigg, D.E., Pugh, J.D., Gelder, L. and Myers, H. (2016) Foundations of a Nursing-Sensitive Outcome Indicator Suite for Monitoring Public Patient Safety in Western Australia. Collegian, 23, 167-181.

https://doi.org/10.1016/j.colegn.2015.03.007 
[27] Needleman, J., et al. (2002) Nurse-Staffing Levels and the Quality of Care in Hospitals. The New England Journal of Medicine, 346, 1715-1722. https://doi.org/10.1056/NEJMsa012247

[28] Aiken, L.H., et al. (2003) Educational Levels of Hospital Nurses and Surgical Patient Mortality. JAMA, 290, 1617-1623. https://doi.org/10.1056/NEJMsa012247

[29] Potter, P., et al. (2003) Identifying Nurse Staffing and Patient Outcome Relationships: A Guide for Change in Care Delivery. Nursing Economic, 21, 158-166.

[30] Dunton, N., Gajewski, B. and Taunton, R.L. (2004) Nurse Staffing and Patient Falls on Acute Care Hospital Units. Nursing Outlook, 52, 53-59. https://doi.org/10.1016/j.outlook.2003.11.006

[31] Barkell, N.P., Killinger, K.A. and Schultz, S.D. (2002) The Relationship between Nurse Staffing Models and Patient Outcomes: A Descriptive Study. Journal of Clinical Outcomes Management, 6, 27-33. 
Appendix A: NSIs

\begin{tabular}{|c|c|c|}
\hline & Structure NSIs & Citation \\
\hline 1. & Working hours per patient days & [16] [17] \\
\hline 2. & Nursing staff supply (Quantity/intensity) & [4] [17] \\
\hline 3. & $\begin{array}{l}\text { Nursing staff supply } \\
\text { (Quality/training/experience) skill }\end{array}$ & [4] [17] \\
\hline 4. & Nursing staff supply (Patient classification) systems & [4] \\
\hline 5. & $\begin{array}{c}\text { Working conditions } \\
\text { (Support resources, Physical facilities, Material resources) }\end{array}$ & [4] \\
\hline 6. & $\begin{array}{c}\text { Working conditions } \\
\text { (Employment conditions, Stability, Workload) }\end{array}$ & [4] \\
\hline 7. & Staff maintenance (Satisfaction at work) & [4] \\
\hline 8. & $\begin{array}{l}\text { Staff maintenance } \\
\text { (Work-related accidents, injuries, illnesses) }\end{array}$ & [4] \\
\hline 9. & Staff maintenance (Retention/turnover) & [4] [17] [18] \\
\hline 10. & Staff maintenance (Absenteeism) & [4] \\
\hline 11. & Economic sustainability (Cost of resources) & [4] \\
\hline 12. & $\begin{array}{c}\text { Economic sustainability } \\
\text { (Cost per case-mix or patient-day) }\end{array}$ & {$[4]$} \\
\hline \multirow[t]{2}{*}{13.} & Nurse-Bed ratio & [19] \\
\hline & Process NSIs & \\
\hline 1. & Delirium observation & {$[20][21]$} \\
\hline 2. & Malnutrition screen & [20] [21] \\
\hline 3. & Pain assessment & [17] [20] [21] \\
\hline 4. & Communication N-P & [22] \\
\hline 5. & Collaboration N-P & [22] \\
\hline 6. & Conflict resolution N-P & [22] \\
\hline 7. & Nurse decision making & [22] \\
\hline 8. & Inter unit work relations & [22] \\
\hline 9. & Restraint application & {$[4][16][17]$} \\
\hline 10. & $\begin{array}{c}\text { Nursing processes } \\
\text { Assessment, planning \& evaluation }\end{array}$ & [4] \\
\hline 11. & Problems \& symptoms management & [4] \\
\hline 12. & Promotion/Prevention & [4] \\
\hline 13. & Hospital community integration/Discharge planning & [4] \\
\hline 14. & Deployment of scope of practice & {$[4]$} \\
\hline 15. & $\begin{array}{l}\text { Patient centrality in the nursing care delivery process } \\
\text { (Continuity, reactivity, timeliness, coordination) }\end{array}$ & {$[4]$} \\
\hline 16. & $\begin{array}{l}\text { Patient centrality in the nursing care delivery } \\
\text { process (Patient/family involvement) }\end{array}$ & {$[4]$} \\
\hline
\end{tabular}




\section{Continued}

17. Patient centrality in the nursing care delivery process

(Responsiveness to patients' needs and expectations)

Nursing work environment

18.

Nursing work environment characteristics (Perceived autonomy, role tension, collaboration)

19.

20.

1.

2.

3.

4.

5.

6.

7.

8.8

9.

10.

11.

12.

13.

14.

15.

16.

17.

18.

19.

Professional satisfaction

Job burnout

Outcome NSIs

Pressure injury

Mortality rate

Fall rate

Patient satisfaction

Central line infection rates

Medication error

Failure to rescue

Job burnout

Length of stay

Catheter associated urinary tract infection

Hospital acquired pneumonia

Intra venous infection

Patient comfort and quality of life related to care: Hygiene

Patient comfort and quality of life related to care: Symptoms management (e.g. pain, nausea, dyspnea, fever)

Patient comfort and quality of life related to care: Incontinence

Patient empowerment: Ability to achieve appropriate self-care

Patient empowerment: Adoption of health-promoting behaviors

Patient functional status (physical, nutritional)

Readmissions
[4]

[16] [17] [20] [24] [25] [26]

[4] [20] [23] [26] [27] [28]

[4] [16] [17] [22] [24]

[25] [26] [29] [30]

[22] [31]

[16]

[4] [16] [29]

[4] [23] [26] [27] [28]

[27] [31]

[4] [24] [26] [27] [31]

[4] [24] [25] [26] [27]

[4] [17]

[4]

[4]

$[4$ 